\title{
Population genetics of the invasive ctenophore Mnemiopsis leidyi in Europe reveal source-sink dynamics and secondary dispersal to the Mediterranean Sea
}

\author{
Sören Bolte ${ }^{1, *}$, Veronica Fuentes ${ }^{2}$, Holger Haslob ${ }^{3}$, Bastian Huwer ${ }^{4}$, \\ Delphine Thibault-Botha ${ }^{5}$, Dror Angel ${ }^{6}{ }_{\text {, Bella Galil }}{ }^{7}$, Jamileh Javidpour ${ }^{8}$, \\ Anthony G. Moss $^{9}$, Thorsten B. H. Reusch ${ }^{1}$
}

${ }^{1}$ Evolutionary Ecology of Marine Fishes, and ${ }^{8}$ Marine Food Webs, GEOMAR Helmholtz Centre for Ocean Research Kiel, Düsternbrooker Weg 20, 24105 Kiel, Germany

${ }^{2}$ Institut de Ciències del Mar (CSIC), 08003 P. Marítim de la Barceloneta 37-49, 08003 Barcelona, Spain

${ }^{3}$ Thünen Institute of Sea Fisheries, Palmaille 9, 22767 Hamburg, Germany

${ }^{4}$ National Institute of Aquatic Resources, Technical University of Denmark, Charlottenlund Castle, 2920 Charlottenlund, Denmark ${ }^{5}$ Aix Marseille Université, CNRS/INSU, IRD, Mediterranean Institute of Oceanography (MIO), UM 110, 13288 Marseille, France

${ }^{6}$ Department of Maritime Civilizations, Leon H. Charney School for Marine Science, University of Haifa, Mt Carmel, Haifa 31905, Israel

${ }^{7}$ National Institute of Oceanography, Israel Oceanographic \& Limnological Research, POB 8030, Haifa 31080, Israel ${ }^{9}$ Biological Sciences, Auburn University, 331 Funchess Hall, Auburn, Alabama 36849, USA

\begin{abstract}
Repeated invasions of European waters by the ctenophore Mnemiopsis leidyi offer a unique opportunity to study population dynamics and dispersal in gelatinous zooplankton. Here we followed population establishment in 2 recently invaded areas, the North and Baltic Seas, and analysed changes in population structure during a 3 yr interval using 7 highly polymorphic microsatellites comprising 191 alleles. A second goal was to reconstruct routes of recent invasive range expansion into the Mediterranean Sea. During the study period (2008 to 2010), populations in the North Sea and Western Baltic Sea maintained their allelic composition with virtually unchanged levels of genetic diversity and between-population differentiation, demonstrating limited gene flow between the 2 regions and successful reproduction in both areas. In contrast, at the eastern distribution limit in the central Baltic (Bornholm Basin), the same measures fluctuated between years and genetic diversity decreased from 2008 to 2010. In concordance with prior ecological observations, this supports the view that $M$. leidyi in the central Baltic is a sink population. In the area of recent range expansion (Mediterranean Sea), we observed high population differentiation: pairwise differentiation $\left(F_{\mathrm{ST}}\right)$ values between sites in Spain, France and Israel were significant and between 0.04 and 0.16. Despite this differentiation, Bayesian clustering and phylogeographic analysis support the hypothesis that all Mediterranean M. leidyi result from a secondary introduction originating from the Black Sea. Our study contributes to growing evidence that multiple invasions of the same species can vary in their degree of genetic diversity and demonstrates how genetic markers can help to resolve whether gelatinous plankton species form self-sustaining populations.
\end{abstract}

KEY WORDS: Invasive species $\cdot$ Source populations $\cdot$ Allelic richness $\cdot$ Jellyfish $\cdot$ Microsatellites Baltic Sea $\cdot$ Mediterranean Sea 


\section{INTRODUCTION}

Gelatinous organisms are evolutionarily ancient members of marine plankton and are ecologically important: their ecological role is increasingly recognized both in the open oceans and anthropogenically affected coastal areas (Purcell et al. 2001, Purcell et al. 2007, Richardson et al. 2009). Moreover, the basal phylogenetic position of the main phyla Cnidaria and Ctenophora (Giribet et al. 2007, Hejnol et al. 2009) has spurred considerable scientific interest in the fields of evolutionary and developmental research (Pang \& Martindale 2008a, Lange et al. 2010). However, the presence of, and underlying causes for, population structure, gene flow and population turnover in jellyfish are currently not well understood, but are of growing interest (Licandro et al. 2010, Stopar et al. 2010, Lee et al. 2013).

Mnemiopsis leidyi is one of the best studied gelatinous plankton species: (1) as a model for developmental biology (Pang \& Martindale 2008b), and (2) due to its wide invasion success, associated with severe ecosystem consequences (reviewed in Purcell et al. 2001, Kideys 2002, Costello et al. 2012). While the native distribution range of $M$. leidyi is the East coast of the Americas from New England to Argentina, it appeared in the Black Sea in the 1980s (Vinogradov et al. 1989). This invasion was accompanied by major ecological changes in the pelagic ecosystem, including a strong decline in fisheries yield (Shiganova \& Bulgakova 2000). In the following years M. leidyi spread into the Caspian Sea (Ivanov et al. 2000), where it reached high abundances and had a strong impact on the plankton community (Finenko et al. 2006). The causative role of $M$. leidyi invasions in restructuring pelagic food webs in the Caspian and Black Seas is still controversial (Bilio \& Niermann 2004). Nevertheless, this ctenophore is a voracious zooplankton consumer and can deplete standing stocks of zooplankton within hours to days when abundant (Finenko et al. 2006, Roohi et al. 2010). Hence, it is well conceivable that it contributed to observed regime shifts by competing with zooplanktivorous fish (Dumont et al. 2004, Daskalov et al. 2007).

Mnemiopsis leidyi had been sporadically observed in the eastern Mediterranean Sea (Kideys \& Niermann 1994, Shiganova et al. 2001), but only recently have blooms spread across the entire Mediterranean region, from Israel to Spain (Boero et al. 2009, Fuentes et al. 2010), suggesting a considerable lag time from first introduction to population growth in this region.
In Northern Europe, Mnemiopsis leidyi has been documented since 2005/2006 in both the North and Baltic Seas (Faasse \& Bayha 2006, Javidpour et al. 2006) as well as along the Norwegian Coast (Oliveira 2007). Both the northward and westward distribution limits in the North Sea are currently not well defined and subject to ongoing research, with the most recent reports from the Belgian coast (Van Ginderdeuren et al. 2012). In the Baltic the eastward distribution limit has been indentified as the Bornholm Basin (Gorokhova et al. 2009, Reusch et al. 2010, Schaber et al. 2011). Here, the ctenophore forms a sink population (Schaber et al. 2011), most likely restricted by environmenal factors: in particular, low salinity values affecting successful reproduction (Jaspers et al. 2011). While adult M. leidyi are able to cope with a wide range in temperature $\left(2-32^{\circ} \mathrm{C}\right)$ and salinity (2-38, Purcell et al. 2001), egg production is dependent on biotic factors such as feeding and environmental conditions (e.g. salinity and temperature) (Baker \& Reeve 1974, Reeve et al. 1989, Jaspers et al. 2011). Possibly, the invasion success of M. leidyi is fostered by hermaphrodite reproduction and high egg production capacity, which can attain $>10000$ eggs per day (Reeve et al. 1989).

The application of high-resolution genetic markers such as microsatellites is the only tool that allows tracking the origin and routes of biological invasions in plankton (Sakai et al. 2001, Estoup \& Guillemaud 2010). Furthermore, measures of genetic diversity (heterozygosity and allelic richness) can identify genetic bottleneck effects that often, but not always, occur during an invasion. If invasions spread under a stepping stone scenario, bottleneck effects may accumulate and provide additional evidence for the directionality of the invasion front. Finally, population genetics can be used to infer hybridisation and admixutre of previously separated gene pools, which may be important because hybridisation between genotypes from different founder populations may increase adaptive potential and invasion success (Ellstrand \& Schierenbeck 2000, Kolbe et al. 2004, Suarez \& Tsutsui 2008).

The establishment of Mnemiopsis leidyi populations in Eurasia is the result of at least 2 independent invasion events (Reusch et al. 2010). An earlier introduction originated from the Gulf of Mexico and reached the Black Sea in the 1980s. M. leidyi subsequently reached the Caspian Sea following a stepping stone model, with concomitant declines in allelic richness. A second independent introduction into northern European waters had its source in coastal waters of New England. Interestingly, the 
Baltic Sea population has a higher allelic richness than the North Sea population, indicating that the primary invasion could have been into the Baltic Sea. Alternatively, the 2 regions could have been colonized by differing magnitudes of propagule numbers from the US East Coast. In adddition to the results of Reusch et al. (2010) another study (Ghabooli et al. 2001), based on the variable sites in internal transcribed spacers, independently found evidence for 2 invasion events into European waters. The latter study further demonstrated that M. leidyi in South American waters (i.e. Argentina) has a very different genotype compared to specimens found in European waters, and thus cannot be considered as a potential source for these invasions.

Currently it is unclear whether the newly established populations in the North and Baltic Seas are temporarily stable, and whether the unexpected divergence of diversity will persist. Furthermore, the stability of population genetic measures at the distribution margin in the Central Baltic (Bornholm Basin) may be instructive for detection of successful selfsustaining reproduction and exchange with adjacent areas. With respect to the recent establishment in the Mediterranean Sea, the source of the population expansion, as well as the diversity of the newly founded populations, is unknown. Hence, the specific aims of this study were to (1) examine the temporal stability of the newly established ctenophore populations in the North and Baltic Seas, (2) identify the source(s) for the $M$. leidyi populations in the Mediterranean Sea, and (3) test for possible hybridisation between individuals originating from the 2 independent introductions.

\section{MATERIALS AND METHODS}

\section{Sampling}

Samples of Mnemiopsis leidyi were collected either by surface dipping, scuba diving or with different plankton nets; sampling locations and years are displayed in Table 1. Animals were dried individually on filter paper and DNA was extracted and analysed as described previously (Reusch et al. 2010). For the Northern time series, M. leidyi from the 3 locations (Helgoland, Kiel Bight and Bornholm Basin) were analysed for 2008 and 2010 from data collected in this study. We used published data for the same locations for the 2009 analyses (Reusch et al. 2010), thus continuous sampling over 3 years was obtained. From the Mediterranean Sea, 3 different sites (Mar- seille, Barcelona, and Haifa) were sampled: these were analysed together with published data from native and invaded habitats (Reusch et al. 2010), to investigate possible invasion routes into this region.

\section{Genetic analysis}

We analyzed polymorphism at 7 microsatellite loci (Reusch et al. 2010) using multiplex PCR with fluorescently labelled primers and subsequent electrophoretic separation on an ABI3130xl genetic analyzer. Raw electropherograms were binned and their alleles called using the software GENEMAPPER (Applied Biosystems). All allele calls were verified by eye and samples with missing data for more than one locus were excluded from further analysis.

\section{Data analysis}

For the time series data from the northern invasion wave (Table 1, Dataset A) all 7 loci were used. For the Mediterranean samples (Dataset B), one locus (L211) was excluded because it shows poor performance in the southern clade, as described previously (Reusch et al. 2010). The fixation index between subpopulations and total population (pairwise $F_{\mathrm{ST}}$ significance level $\mathrm{p}<0.05$ ) was calculated for both datasets with the software Genetix (Belkhir et al. 1996). To compensate for multiple testing, the false discovery rate (FDR) approach (Benjamini \& Hochberg 1995) was applied and adjusted q-values were calculated from the $\mathrm{p}$-value distributions. The q-value is defined as the FDR-adjusted analogue of the p-value, i.e. the value of an individual hypothesis test is the minimum FDR at which a test is called significant. The significant q-value for the 36 comparisons of the time series (Dataset A) was 0.026 while for the 136 pairwise comparisons of the population genetic overview (Dataset B) the FDR-adjusted q-value was 0.007.

Before calculating the mean number of alleles, rarefaction was applied to compensate for differences in sample size between sites and/or years (Leberg 2002). For this calculation of allelic richness, data were imported into the software HP-Rare (Kalinowski 2005). The time series data were subjected to rarefaction according to the smallest sample size of 13 individuals and the mean number of alleles over 7 loci was calculated. Dataset B, including the Mediterranean samples, was subjected to rarefaction to a size of 15 samples and allelic richness calculated over 6 loci. The mean diversity measures of allelic rich- 
Table 1. Mnemiopsis leidyi. Samples analysed in this study, sampling locations, coordinates, collectors and number of samples included in the final analysis. Dataset A: Samples from the time series of the northern invasion wave. Dataset B: Population genetic overview including samples from the native range (Gulf of Mexico, NW Atlantic), from the invaded seas in Northern Europe (North Sea, Kattegat, Baltic Sea) and from the southern invasion wave (Black Sea, Caspian Sea and Mediterranean Sea). Samples marked with an asterisk* are taken from Reusch et al. (2010)

\begin{tabular}{|c|c|c|c|c|c|c|}
\hline Sampling site & Region & Year & Code & Location & Collector & $\mathrm{N}$ \\
\hline \multicolumn{7}{|l|}{ Dataset A } \\
\hline Helgoland & North Sea & 2008 & NO-HE08 & $54^{\circ} 11^{\prime} \mathrm{N}, 07^{\circ} 53^{\prime} \mathrm{E}$ & Hendrike Hammer (AWI) & 34 \\
\hline Helgoland & & 2009 & NO-HE09* & $54^{\circ} 11^{\prime} \mathrm{N}, 07^{\circ} 53^{\prime} \mathrm{E}$ & Phillip Schubert (GEOMAR) & 46 \\
\hline Helgoland & & 2010 & NO-HE10 & $54^{\circ} 11^{\prime} \mathrm{N}, 07^{\circ} 53^{\prime} \mathrm{E}$ & Phillip Schubert (GEOMAR) & 40 \\
\hline $\begin{array}{l}\text { Kiel Bight } \\
\quad \text { (Maasholm) }\end{array}$ & Baltic Sea & 2008 & BA-KB08* & $5441^{\prime} \mathrm{N}, 1000^{\prime} \mathrm{E}$ & $\begin{array}{l}\text { Maximiliane Sparwel } \\
\text { (Uni Münster/ GEOMAR) }\end{array}$ & 42 \\
\hline Kiel Bight (Kiel) & & 2009 & BA-KB09* & $54^{\circ} 25^{\prime} \mathrm{N}, 10^{\circ} 12^{\prime} \mathrm{E}$ & Sören Bolte (GEOMAR) & 21 \\
\hline Kiel Bight (Kiel) & & 2010 & BA-KB10 & $54^{\circ} 25^{\prime} \mathrm{N}, 10^{\circ} 12^{\prime} \mathrm{E}$ & Sören Bolte (GEOMAR) & 22 \\
\hline Bornholm Basin & Baltic Sea & 2008 & BA-BB08 & $55^{\circ} 11^{\prime} \mathrm{N}, 15^{\circ} 32^{\prime} \mathrm{E}$ & Holger Haslob (GEOMAR) & 13 \\
\hline Bornholm Basin & & 2009 & BA-BB09* & $55^{\circ} 11^{\prime} \mathrm{N}, 15^{\circ} 32^{\prime} \mathrm{E}$ & Bastian Huwer (DTU Aqua) & 42 \\
\hline Bornholm Basin & & 2010 & BA-BB10 & $55^{\circ} 11^{\prime} \mathrm{N}, 15^{\circ} 32^{\prime} \mathrm{E}$ & Sören Bolte (GEOMAR) & 23 \\
\hline \multicolumn{7}{|l|}{ Dataset B } \\
\hline USA Port Aransas & Gulf of Mexico & 2009 & GM-PA* & $27^{\circ} 50^{\prime} \mathrm{N}, 97^{\circ} 03^{\prime} \mathrm{W}$ & Anthony G. Moss (Auburn Univ.) & 19 \\
\hline USA Galveston Bay & Gulf of Mexico & 2009 & GM-GB* & $29^{\circ} 17^{\prime} \mathrm{N}, 94^{\circ} 52^{\prime} \mathrm{W}$ & Anthony G. Moss (Auburn Univ.) & 20 \\
\hline USA Panacea & Gulf of Mexico & 2009 & GM-PC* & $30^{\circ} 00^{\prime} \mathrm{N}, 84^{\circ} 20^{\prime} \mathrm{W}$ & $\begin{array}{l}\text { Jack Rudloe (Gulf Specimen } \\
\text { Marine Lab) }\end{array}$ & 33 \\
\hline USA Woods Hole & NW Atlantic & 2009 & NWA-WH* & $41^{\circ} 31^{\prime} \mathrm{N}, 70^{\circ} 40^{\prime} \mathrm{W}$ & Woods Hole MBL Specimen Service & 45 \\
\hline Helgoland & North Sea & 2009 & NO-HE09* & $54^{\circ} 11^{\prime} \mathrm{N}, 07^{\circ} 53^{\prime} \mathrm{E}$ & Philip Schubert (GEOMAR) & 46 \\
\hline $\begin{array}{l}\text { Kristineberg } \\
\text { Sweden }\end{array}$ & Kattegat & 2009 & KA-KRS* & $58^{\circ} 24^{\prime} \mathrm{N}, 11^{\circ} 24^{\prime} \mathrm{E}$ & $\begin{array}{l}\text { Lene Friis Möller } \\
\text { (University of Gothenburg) }\end{array}$ & 37 \\
\hline $\begin{array}{l}\text { Kiel Bight } \\
\quad \text { (Maasholm) }\end{array}$ & Baltic Sea & 2008 & BA-KB08* & $5441^{\prime} \mathrm{N}, 1000^{\prime} \mathrm{E}$ & $\begin{array}{l}\text { Maximiliane Sparwel } \\
\text { (Uni Münster/ GEOMAR) }\end{array}$ & 42 \\
\hline $\begin{array}{l}\text { Kiel Bight } \\
\quad \text { (Kiel Fjord) }\end{array}$ & Baltic Sea & 2009 & BA-KB09* & $54^{\circ} 25^{\prime} \mathrm{N}, 10^{\circ} 12^{\prime} \mathrm{E}$ & Sören Bolte (GEOMAR) & 21 \\
\hline Fehmarn Belt & Baltic Sea & 2009 & BA-FEM* & $54^{\circ} 30^{\prime} \mathrm{N}, 11^{\circ} 20^{\prime} \mathrm{E}$ & Sören Bolte (GEOMAR) & 48 \\
\hline Bornholm Basin & Baltic Sea & 2009 & BA-BB09* & $55^{\circ} 11^{\prime} \mathrm{N}, 15^{\circ} 32^{\prime} \mathrm{E}$ & Bastian Huwer (DTU Aqua) & 48 \\
\hline Black Sea Bulgaria & Black Sea & 2009 & BS-B* & $43^{\circ} 11^{\prime} \mathrm{N}, 27^{\circ} 57^{\prime} \mathrm{E}$ & $\begin{array}{l}\text { Kremena Stefanova (Bulgarian } \\
\text { Inst. of Oceanology) }\end{array}$ & 15 \\
\hline Black Sea Ukraine & Black Sea & 2009 & BS-U* & $44^{\circ} 37^{\prime} \mathrm{N}, 33^{\circ} 31^{\prime} \mathrm{E}$ & $\begin{array}{l}\text { Alexandra Gubanova (Inst. } \\
\text { Biology of the Southern Seas) }\end{array}$ & 48 \\
\hline Black Sea Turkey & Black Sea & 2009 & BS-T* & $42^{\circ} 01^{\prime} \mathrm{N}, 35^{\circ} 08^{\prime} \mathrm{E}$ & Levent Bat (Sinop Univ.) & 23 \\
\hline Caspian Sea Iran & Caspian Sea & 2009 & CAS-I* & $36^{\circ} 48^{\prime} \mathrm{N}, 53^{\circ} 07^{\prime} \mathrm{E}$ & Jamileh Javid (GEOMAR) & 22 \\
\hline Israel & Mediterr. Sea & 2010 & MS-ISD & $32^{\circ} 51^{\prime} \mathrm{N}, 35^{\circ} 01^{\prime} \mathrm{E}$ & Dror Angel (Haifa Univ.) & 24 \\
\hline Barcelona Spain & Mediterr. Sea & 2010 & MS-BS & $41^{\circ} 20^{\prime} \mathrm{N}, 02^{\circ} 11^{\prime} \mathrm{E}$ & $\begin{array}{l}\text { Veronica Fuentes } \\
\text { (ICM-CSIC Barcelona) }\end{array}$ & 35 \\
\hline Marseille France & Mediterr. Sea & 2010 & MS-MS & $43^{\circ} 26^{\prime} \mathrm{N}, 05^{\circ} 06^{\prime} \mathrm{E}$ & $\begin{array}{l}\text { Delphine Thibault Botha, } \\
\text { (LOPDMarseille) }\end{array}$ & 19 \\
\hline
\end{tabular}

ness were tested for significant differences between groups. For both datasets (A and B) the mean number of alleles were normally distributed (Shapiro Wilk Test; $\mathrm{p}>0.05$ ) and the data met the assumptions of ANOVA. For the northern time series we grouped all 3 years from one location and tested over all 7 loci. We performed a repeated-measures ANOVA, testing site against number of alleles (NA) for each locus; this was followed by a pairwise $t$-test. For the southern invasion, event sites were grouped according to expected introduction sequence: native (Gulf of
Mexico), primary invasion (Black Sea) and putative secondary invasions (Caspian Sea and Mediterranean Sea), and we performed a 1-way ANOVA and a pairwise $t$-test. All statistical analysis were performed in the $\mathrm{R}$ software package (www.r-project. org). All maps were created with Ocean Data View (Schlitzer 2002).

For detection of population structure without prior geographic assumptions, the Bayesian clustering software STRUCTURE (Pritchard et al. 2000) was applied to both Datasets A and B. For both analyses 
we used the genetic admixture model and correlated allele frequencies between populations, 10000 reiterations for the burn-in and 100000 Markov chain Monte Carlo (MCMC) repetitions. For the population genetic overview containing 17 sampling sites (Dataset B), 6 replicates were run for each value of $K$ (number of clusters) from 1 to 10 . According to the method proposed by Evanno et al. (2005), the uppermost level of population structure can be detected as an increase in log likelihood as $K$ is increased. For this data set, the strongest increase in log likelihood was observed for 2 clusters (data not shown) as $K$ increased, additional sublevels of structuring were observed both within the southern clade $(K=3)$ and in the northern clade $(K=4)$. For the northern time series (Dataset A), containing samples from 3 sampling sites, 6 replicate runs were made for clusters from 1 to 5 .

To investigate relatedness within the southern invasion event and to specifically identify the source of the Mediterranean populations, an allele frequency data set containing all southern sites was generated in Genetix (Belkhir et al. 1996) and exported into the PHYLIP package (Felsenstein 1993). A neighbour-joining (NJ) tree based on Cavalli-Sforza's and Edward's chord distance was generated (Cavalli-Sforza \& Edwards 1967) with 1000 bootstrap replicates using the PHYLIP subprograms SEQBOOT, GENDIST, NEIGHBOUR; CONSENSE and DRAWTREE. The resulting NJ tree was visualized with TreeView (Page 1996).

To evaluate the different invasion/expansion scenarios within the framework of coalescence theory, we ran several models implemented in MIGRATE-N v.3.3.1 (Beerli 2006). Analyses followed the theoretical considerations outlined in Beerli \& Palczewski (2010), using a Brownian motion model (see Table S4 in the Supplement at www.int-res.com/articles/ suppl/m485p025_supp.pdf).

We intended to compare 3 different scenarios of gene flow for the southern invasion: (1) full model, (2) introduction from the Gulf of Mexico into the Black Sea and expansion from the Black Sea into the Mediterranean Sea, and (3) introduction into the Black Sea from the Gulf of Mexico and secondary expansion to the Mediterranean Sea both from the Black Sea and Northern Europe. Convergence of model parameters was evaluated based on posterior distributions of parameters and estimates between replicate runs (Bertorelle et al. 2009).

\section{RESULTS}

Given that Mnemiopsis leidyi is a holoplanktonic species, we observed high levels of genetic structuring between regions as well as substructuring within regions, demonstrated by significant $F_{\text {ST }}$ values (after correction) even over short geographic distances (Table 2, Table S1 in the Supplement). For the 136 pairwise comparisons of the population genetic overview, 120 were significant (Dataset A, Table S1). In the northern time series from the North and Baltic Seas, 19 out of 36 comparisons were significant (Dataset B, Table 2). The strong genetic structuring allows identification of different clusters within the native and invaded ranges, through Bayesian clustering without prior definition of populations (Fig. 1). A very clear separation between both invasion waves was observed (Fig. 1a). With increasing number of clusters, genetic subdivision becomes visible within the (older) southern invasion (Fig. 1b) and the (younger) northern invasion (Fig. 1C).

Table 2. Mnemiopsis leidyi. Fixation index between subpopulations and the total population $\left(F_{\mathrm{ST}}\right)$ in the North and Baltic Seas for the years 2008 to 2010. Annual samples from 1 North Sea (Helgoland NO-HE) and 2 Baltic Sea sites (Kiel Bight BA-KB, Bornholm Basin BA-BB). Pairwise $F_{\mathrm{ST}}$ (above diagonal) and associated p-values (lower diagonal) are shown. Significant $F_{\mathrm{ST}}$ values are indicated with an asterisk ${ }^{*}$

\begin{tabular}{|lccccccccc|}
\hline & NO-HE08 & NO-HE09 & NO-HE10 & BA-KB08 & BA-KB09 & BA-KB10 & BA-BB08 & BA-BB09 & BA-BB10 \\
\hline NO-HE08 & & 0.005 & 0.000 & $0.030^{*}$ & $0.024^{*}$ & $0.049^{*}$ & $0.034^{*}$ & $0.047^{*}$ & $0.041^{*}$ \\
NO-HE09 & 0.114 & & 0.000 & $0.034^{*}$ & $0.030^{*}$ & $0.056^{*}$ & $0.046^{*}$ & $0.040^{*}$ & $0.045^{*}$ \\
NO-HE10 & 0.536 & 0.442 & & $0.024^{*}$ & $0.018^{*}$ & $0.042^{*}$ & $0.033^{*}$ & $0.034^{*}$ & $0.035^{*}$ \\
BA-KB08 & 0.000 & 0.000 & 0.000 & & 0.000 & 0.001 & 0.000 & 0.004 & 0.009 \\
BA-KB09 & 0.001 & 0.000 & 0.000 & 0.891 & & 0.004 & 0.000 & 0.005 & 0.005 \\
BA-KB10 & 0.000 & 0.000 & 0.000 & 0.409 & 0.208 & & 0.008 & 0.004 & 0.001 \\
BA-BB08 & 0.002 & 0.000 & 0.000 & 0.588 & 0.480 & 0.152 & & 0.015 & 0.006 \\
BA-BB09 & 0.000 & 0.000 & 0.000 & 0.079 & 0.151 & 0.152 & 0.042 & 0.012 \\
BA-BB10 & 0.000 & 0.000 & 0.000 & 0.047 & 0.203 & 0.421 & 0.245 & 0.026 & $0.012^{*}$ \\
\hline
\end{tabular}


a

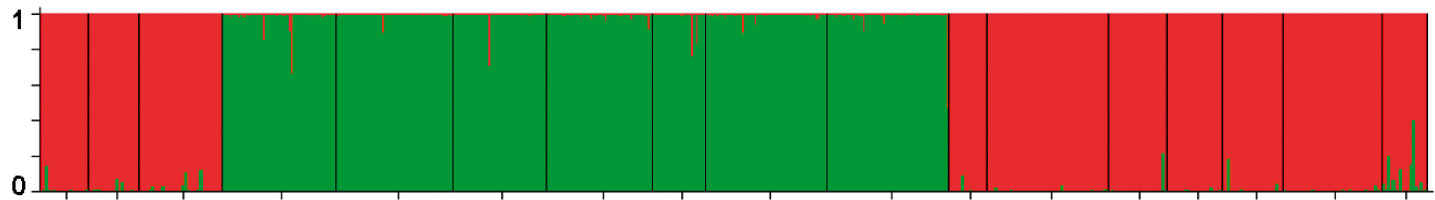

b

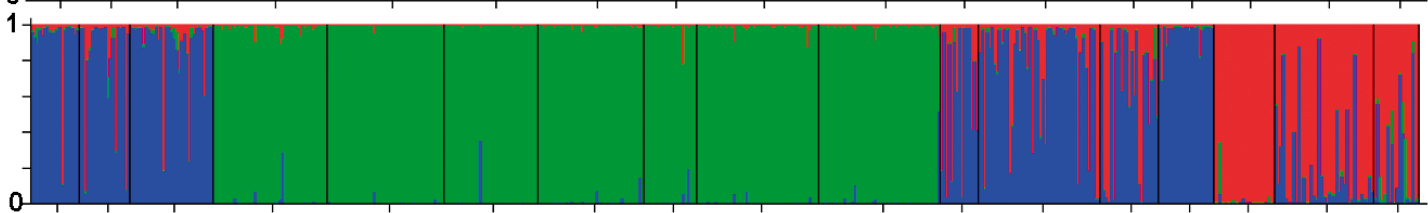

c

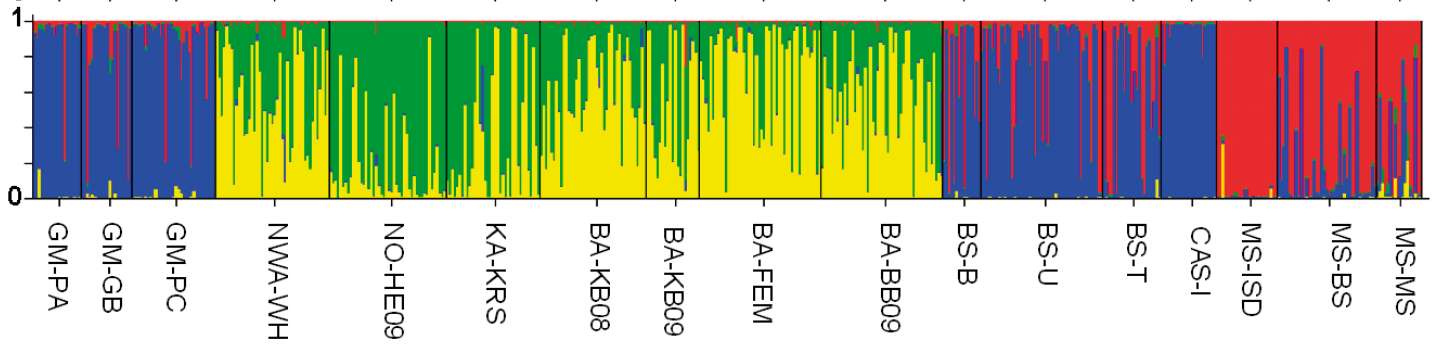

Fig. 1. Mnemiopsis leidyi. Bar plots for clustering analysis of all 17 sites. Three sites across the Mediterranean Sea are clustered in relation to reference samples from the native and invaded range (sample description Table 1). Populations are ordered according to their geographic position and time since invasion. Colours represent the genetic clusters; each bar represents 1 individual and the colour is the probability of that individual for each cluster. Genetic structuring for (a) $K=2$, (b) $K=3$ and (c) $K=4$ clusters were based on 6 microsatellite loci. (a) Bar plot with 2 clusters; the plot shows subdivision between the independent northern and southern invasion waves (red and green). (b) For 3 clusters, subdivision within the southern clade becomes visible (red and blue). (c) Four clusters show additional substructure within the northern group between the North and Baltic Seas (green and yellow)

\section{Time series northern invasion}

During the period from 2008 to 2010, the difference in genetic diversity (Fig. 2b) among the North Sea and Baltic Sea sites showed only small and nonsignificant changes (Dataset A). Divergence between the regions was reflected in significant $(\mathrm{p}<0.05)$ pairwise $F_{\mathrm{ST}}$ values (0.018 to 0.056 , Table 2 ). Genetic diversity was significantly different between the North and Baltic Seas in all years, with comparisons among Central/Western Baltic and the North Sea always highly significant $(p<0.001)$. In contrast, within the Baltic there was no significant difference $(p=0.084$, Table S2 in the Supplement). The mean number of alleles was consistently higher in the Western Baltic than in the North Sea (Fig. 2b). The levels of allelic richness stayed virtually constant for Helgoland and Western Baltic Sea, whereas in the

Fig. 2. Mnemiopsis leidyi. Population time series in Northern Europe: (a) the 3 annual sampling sites, one from the North Sea (Helgoland NO-HE) and 2 Baltic Sea sites (Kiel Bight BA-KB, Bornholm Basin BA-BB), (b) allelic richness for 7 microsatellite loci for the years 2008 to 2010. See 'Materials and methods: Data analysis' a

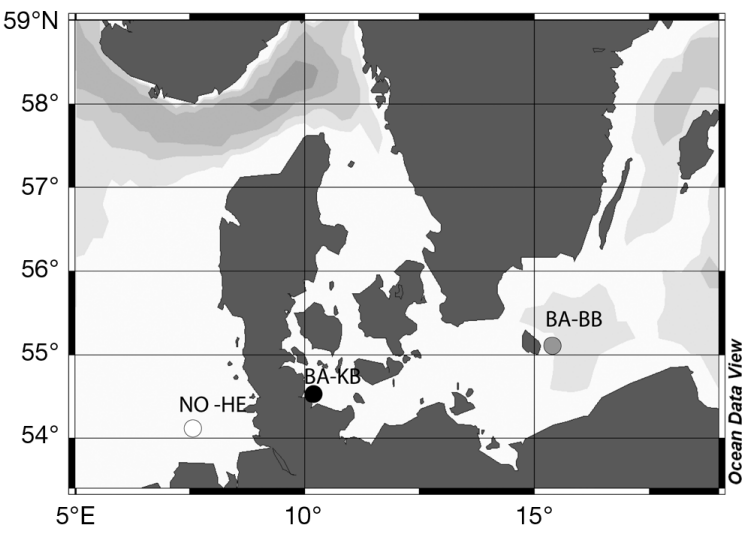

b

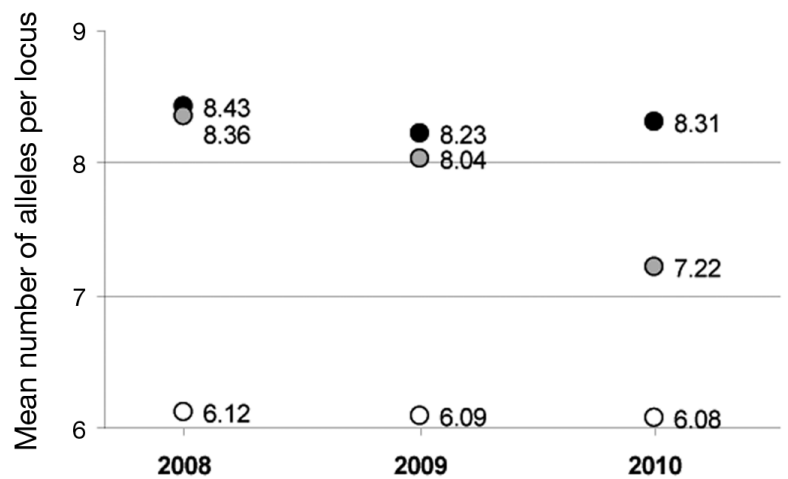




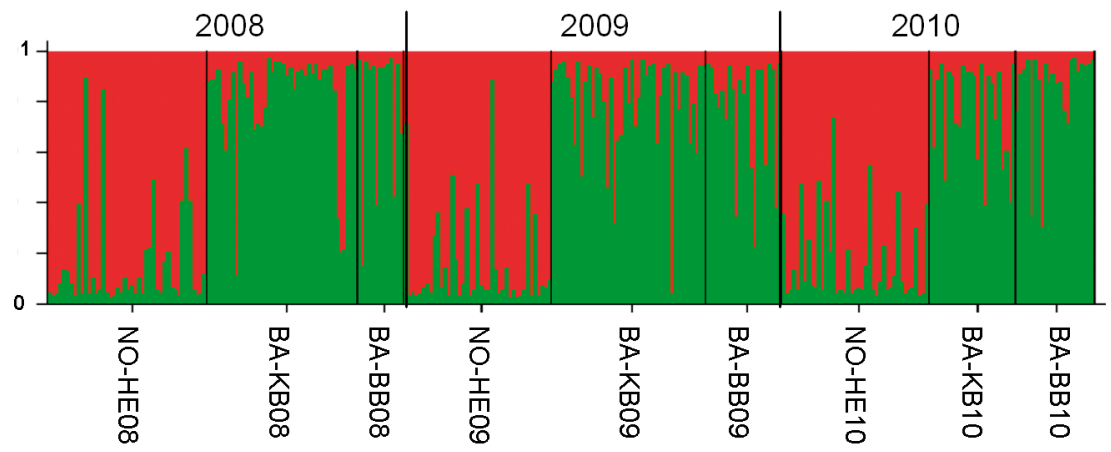

Fig. 3. Mnemiopsis leidyi. Bar plot for clustering analysis of time series data based on 7 microsatellite loci. Each bar represents one individual; colours show the probability of assignment to each of 2 different clusters (red: North Sea; green: Baltic Sea). Three locations were sampled from 2008 to 2010: 1 location from the North Sea (Helgoland, NO-HE) and 2 Baltic Sea sites (Kiel Bight, BA-KB and Bornholm Basin, BA-BB)

South-Central Baltic we detected stronger fluctuations and a downward trend (Fig. 2b). No novel genotypes from known or unknown source regions were detected, which would have been identified by high $F_{\mathrm{ST}}$ values between years and inconsistent clustering in the STUCTURE plot (Fig. 3). Likewise, the Bayesian clustering analysis consistently assigned the samples from both regions into different groups for all 3 years (Fig. 3). When samples from the same site were compared between years, there was no divergence observed for Helgoland or Western Baltic, while for the Bornholm Basin one comparison between years was significant (BA-BB09 $\times$ BA-BB10, $F_{\mathrm{ST}}=0.012, \mathrm{p}<0.05$, Table 2 ).

\section{Southern invasion and spread into the Mediterranean Sea}

When applying Bayesian clustering to Dataset B, all Mediterranean Mnemiopsis leidyi were firmly placed into the previously identified southern cluster that originates from the Gulf of Mexico (Fig. 1a). The Mediterranean samples do not form a new separate cluster (Fig. 1a-c), suggesting that no novel genotypes from yet another source were present. If the number of clusters was increased to $K=3$ (Fig. 1b) additional genetic subdivision became visible: Caspian Sea (CAS) and Mediterranean Sea (MS) samples were grouped into different clusters while the Black Sea (BS) samples have some probability for both clusters. M. leidyi from Barcelona had the smallest pairwise divergence compared to Black Sea Turkey (MS-BS $\times$ BS-T, $F_{\mathrm{ST}}=0.051, \mathrm{p}<0.05$ ) and Bulgaria samples (MS-BS $\times \mathrm{BS}-\mathrm{B}, F_{\mathrm{ST}}=0.070, \mathrm{p}<0.05$ ). Also, for the ctenophores from Marseille, the closest potential source populations were found among the Black Sea samples (MS-MS $\times$ BS-B, $F_{\mathrm{ST}}=0.042, \mathrm{p}<$ $0.05 ;$ MS-MS $\times$ BS-T, $\left.F_{\mathrm{ST}}=0.059, \mathrm{p}<0.05\right)$. M. leidyi from Israel showed lower similarity to potential source populations, with the closest genetic distance to Black Sea Bulgaria samples (MS-ISD $\times \mathrm{BS}-\mathrm{B}, F_{\mathrm{ST}}=$ $0.13, \mathrm{p}<0.05$; Table S1 in the Supplement).

The topology of the NJ tree (Fig. 4) reflected the high divergence in the native range (Gulf of Mexico) and between sites within the newly invaded areas of the Black Sea and Mediterranean Sea, but firmly placed the samples into separate clades for each region. The root for the Mediterranean clade was set in the Black Sea with high statistical support (94\% bootstrap support).

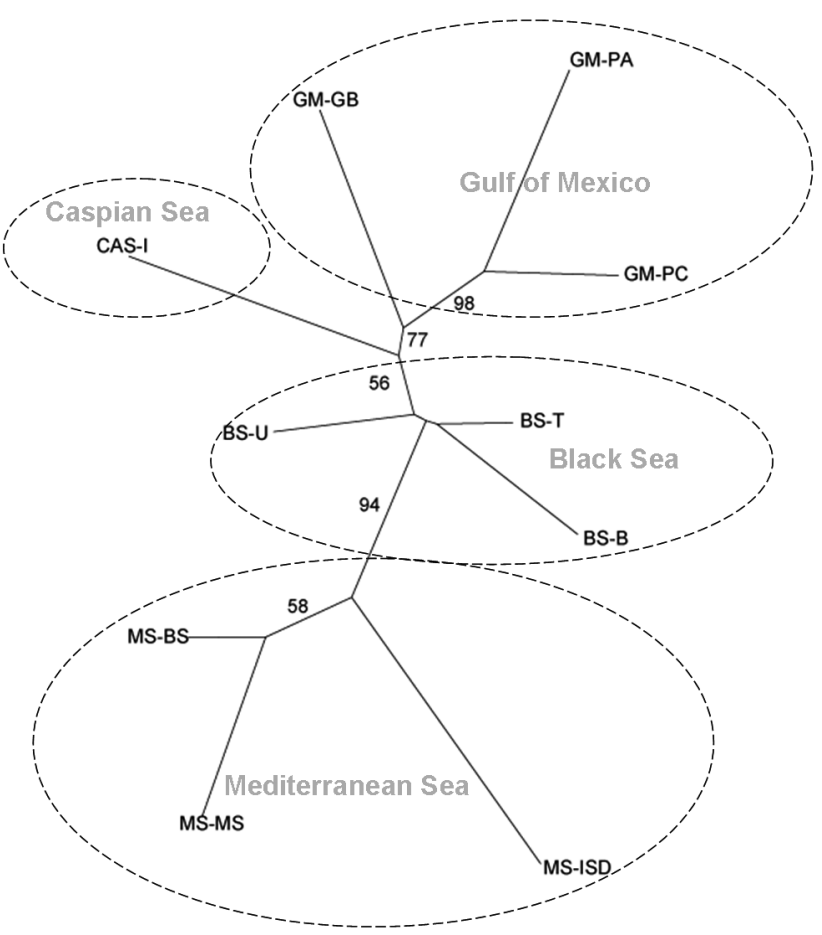

Fig. 4. Mnemiopsis leidyi. Neighbour-joining tree of the southern invasion wave containing samples from the Gulf of Mexico (GM), Black Sea (BS), Caspian Sea (CAS) and Mediterranean Sea (MS) based on Cavalli-Sforza's and Edward's chord distance. Bootstrap values out of 1000 replicates as obtained with PHYLIP (Felsenstein 1993) are given in percent; only values greater $50 \%$ are shown 
Allelic richness for all sites of the southern invasion (Fig. 5) wave was calculated using rarefaction. While they shared the majority of their alleles with Black Sea and Gulf of Mexico ctenophores, the mean number of alleles in samples from Israel (MS-ISD) and Spain (MS-BS) was reduced (Fig. 5b). Samples obtained from France (MS-MS) had a genetic diversity comparable to samples from the Black Sea sites: they shared the majority of alleles with Black Sea populations but also contained some additional alleles as found in the northern clade (New England, North and Baltic Seas). The Bayesian clustering algorithm of STRUCURE gave some of these samples (MS-MS) a low probability of belonging to the northern cluster but assorted all samples with a higher probability into the southern cluster, which remained consistent with increasing $K$ (Fig. 1a-c). Sites were grouped according to expected colonisation sequence, native populations in the Gulf of Mexico (GM-PA, GM-GB, GM-PC), the primary invaded Black Sea (BS-B, BS-U, BST) and the putative secondary invasions in the Caspian and Mediterranean
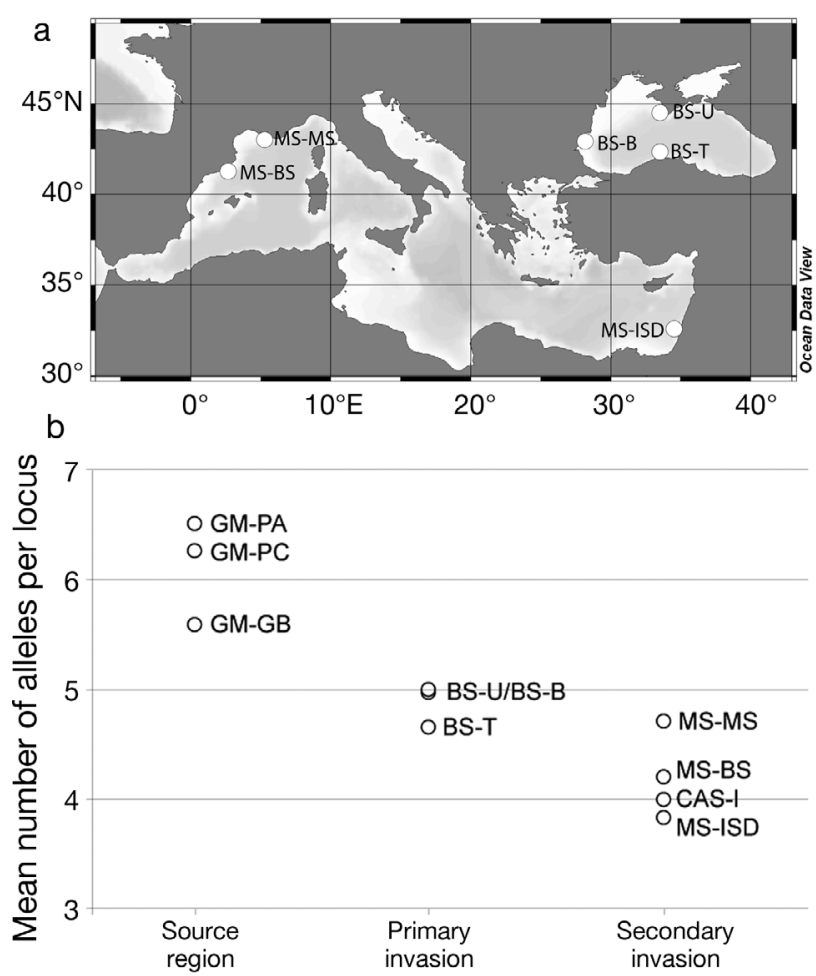

Fig. 5. Mnemiopsis leidyi. Population expansion in Southern Europe: (a) location of sampling sites in the Mediterranean Sea and reference populations in the Black Sea, (b) mean number of alleles per population over 6 microsatellite loci. Samples are grouped on the $x$-axis into putative source populations in the Gulf of Mexico (GM), the primary invaded Black Sea (BS) and the putative secondary invasion in the Caspian Sea (CAS) and Mediterranean Sea (MS)
Seas (CAS-I, MS-ISD, MS-BS, MS-MS). The statistical analysis showed a significant decline in allelic richness between the native populations and the primary invaded Black Sea $(p=0.014)$ while the difference between Black Sea and potential secondary invaded sites in Caspian and Mediterranean Sea was only marginally significant ( $p=0.056$, Table S3 in the Supplement).

Coalescent analysis in MIGRATE-N did not reach stable convergence of model parameters and probabilities (see Table S4 in the Supplement), independent of increased run length or replicate number. Non-convergence of coalescent analysis with microsatellite data is well known (see Beerli 2009). It might reflect the complexity to integrate over several loci (Lack et al. 2012), or may occur in very recent population splits, where time since population divergence is much shorter than time to coalescence (Beerli 2009). In the case of Mnemiopsis leidyi, our other analyses and the published record suggest that the latter is the likely scenario, i.e. that the invasions into European seas and secondary spread represent very recent population splits.

Comparing Mediterranean and Northern European samples, the pairwise $F_{\mathrm{ST}}$ values were consistently high between the 2 regions $\left(F_{\mathrm{ST}} 0.257\right.$ to 0.395 , $\mathrm{p}<0.05$, Table S1); likewise the Bayesian clustering of individual samples with STRUCTURE indicated no mixing between the independently introduced genotypes (Fig. 1).

\section{DISCUSSION}

Mnemiopsis leidyi is a prime example of a globally successful gelatinous plankton species with a wide native distribution and the ability to quickly invade new habitats. Here we provide novel data on introduction pathways and processes that take place after successful introduction into a given region. To this end, we monitored the temporal stability of genetic diversity and divergence.

In the recently invaded North and Baltic Seas, we found no signs of immigration of new genotypes from known or unknown source regions. Instead, a distinct genetic composition was maintained in both seas (Fig. 3). Our microsatellite data revealed both significant and almost constant genetic divergence between Mnemiopsis leidyi populations in North and Western Baltic Sea, combined with little variability across years at the same sampling location (Fig. 3). This demonstrates that at least over the period of 3 years (from 2008 to 2010), gene flow between popu- 
lations in these adjacent seas was limited enough to maintain the difference. This is also supported by our measures of genetic diversity which remain almost constant in both regions, inconsistent with a possible mixing of Baltic and North Sea genotypes. We suggest that such a stable genetic diversity and divergence indicate that $M$. leidyi populations were selfsustaining and successful recruitment took place both in the North Sea and Western Baltic Sea. Our genetic data match recent findings on egg production as a function of salinity. While in the Western Baltic, salinity is sufficient for successful reproduction (>15), substantial declines in reproduction are observed at salinities between 10 and 15 (Jaspers et al. 2011). This may help explain why, at the central Bornholm Basin in the Baltic Sea, we observed the genetic signatures of a sink population (Dias 1996). In addition, allelic richness revealed fluctuations and a general decline at this site during the observation period. The pairwise genetic differences between years within the region were higher than the pairwise distance to the Western Baltic, and statistically significant for one comparison $(2009 \times 2010)$. These population genetic measures support the conclusion that there was no self-sustaining population in the Central Baltic (Schaber et al. 2011). Our interpretation is consistent with data on seasonal phenology and size distribution in this area, which demonstrated that only adult animals occurred after blooms in the Western Baltic, and almost no juveniles or larvae of $M$. leidyi were observed, thus making the Bornholm Basin a sink region (Schaber et al. 2011). Further eastward from the Bornholm Basin, no adults or larvae of $M$. leidyi have been observed (Jaspers et al. 2013) and the reasons for this sink situation have been identified as environmental restrictions regarding reproduction and feeding, related to ambient temperatures, salinities and food availability (Jaspers et al. 2011, Schaber et al. 2011, Lehtiniemi et al. 2012). Source-sink dynamics seem to play an important role in population persistence of $M$. leidyi, and have been described both in the native habitat (Narragansett Bay, Costello et al. 2006) and in the invaded range (Sea of Azov, Purcell et al. 2001, reviewed in Costello et al. 2012).

In contrast to previous years, Mnemiopsis leidyi remained relatively rare throughout the Baltic in 2011 and 2012. The species was completely absent in the Bornholm Basin (H. Haslob \& B. Huwer unpubl.), and no blooms occurred in the Western Baltic during summer and autumn, while only very late blooms occurred in the North Sea followed by scattered sightings in the Western Baltic (J. Javidpour un- publ.). Interestingly, the present study demonstrated that, while in the Western Baltic no changes in genetic diversity or divergence had been observed, this population decline was preceded by a loss of genetic diversity at the distribution margin in the Bornholm Basin. Future monitoring may reveal whether the population recovers, in which case genetic markers may be used to assess whether recovery was achieved by recolonization from the North Sea, or via regeneration of the genetically differentiated Baltic Sea population.

\section{Southern invasion and spread into the Mediterranean Sea}

All newly analyzed southern subpopulations group into one genetic cluster together with Black and Caspian Sea samples, suggesting a stepping-stone scenario of an invasive range expansion. The allelic richness exhibits a significant gradual decline in the order Gulf of Mexico, Black Sea, Caspian Sea/Mediterranean Sea, giving additional support for a secondary invasion from the Black Sea with a loss of allelic richness due to another founder event. The strong genetic divergence is most likely due an initial founder event, and subsequent drift. Among the Mediterranean Sea sites we find even stronger population differentiation than observed among North and Baltic Sea sites, possibly reflecting the influence of bottleneck effects driving genetic differentiation.

In spite of reduced genetic diversity, Mnemiopsis leidyi was able to establish populations across the Mediterranean Sea, from Israel in the east to France and Spain in the west (Fuentes et al. 2010). At the Spanish coast, $M$. leidyi blooms have been observed for the last 3 years and the ctenophore has been monitored in the Ebro delta year round; furthermore, successful reproduction has been observed both in the field and in the laboratory (V. Fuentes et al. unpubl. data). Concomitant observations of $M$. leidyi continue in several coastal lagoons of southern France, where the ctenophore has been observed throughout the year (e.g. Berre Lagoon, le Grec Lagoon, BagesSigean Lagoon, D. Thibault-Botha unpubl. data). At the Israeli coast, $M$. leidyi has been observed annually since 2009 (Fuentes et al. 2010, Galil et al. 2009, 2011). Our genetic analysis demonstrate that all these Mediterranean populations are of Black Sea origin and have clearly diverged from the source region, thus supporting that local populations have established. Considering that, after a lag phase, $M$. leidyi established genetically divergent popula- 
tions across the Mediterranean Sea and general habitat suitability (Siapatis et al. 2008), future spread and bloom events of this invasive species should be carefully monitored.

Because hybridisation between the 2 independently introduced genotypes may release additional adaptive potential (Ellstrand \& Schierenbeck 2000, Kolbe et al. 2004, Suarez \& Tsutsui 2008), an assessment of possible secondary contact was an important aspect of the study. In the sampled populations we found no signs for intermixing of the separated gene pools. For the northern sites, our genetic measures and the Bayesian clustering (Fig. 2) confirm the temporal integrity of the established populations, without influx from the native habitat or southern Europe. Likewise, we found no introgression of northern genotypes into the newly established Mediterranean populations based on pairwise genetic differences and Bayesian Clustering (Fig. 1). The sampled individuals resemble Black Sea genotypes and most populations have reduced genetic diversity, indicative of a secondary founder event. Ctenophores from Southern France showed a slightly higher genetic diversity - about the same level as Black Sea samples and display some alleles that have also been detected in the northern invasion. Many more genetic markers are needed to conclusively determine whether this indicates some ongoing hybridisation and introgression between northern and southern invasion waves, or simply reflects shared ancestral polymorphism and incomplete lineage sorting.

The example of Mnemiopsis leidyi demonstrates that the genetic diversity of the same invasive species may behave very differently between independent invasion events. In the southern invasion, founder events with corresponding genetic bottlenecks seem commonplace, while in the northern invasion there was only a moderate loss of genetic diversity in the North Sea, and no loss of genetic diversity in the Baltic Sea compared to the native range. The 'paradox of invasions' (Sax \& Brown 2000) highlights that invasive species are successful and outcompete local species, even though they often have reduced genetic diversity. Given the hermaphrodite mode of reproduction in $M$. leidyi, our findings underline the importance of reproductive strategies for invasion success, despite losses in genetic diversity (Roman \& Darling 2007). Finally, our study contributes to the growing evidence that not all invasions need to be accompanied by losses of genetic diversity (Rius et al. 2008, Brown \& Stepien 2009) and successful invasions can vary broadly in their degree of genetic diversity (Darling et al. 2008).
Acknowledgements. For collection of specimen we thank the crews of the RV 'Alkor' and RV 'Dana' and the following colleagues: P. Schubert, H. Hammer, L. Friis Möller, M. Acevedo, D. Edelist, N. Nakar, K. Stefanova, A. Gubanova and L. Bat. K. Beining assisted with the laboratory analysis. We also thank P. Beerli for his patient comments on the MIGRATE-N analysis. The study was funded by the DFG (Deutsche Forschungsgemeinschaft) to T.B.H.R. and EU FP 7 project VECTORS (Grant no. 266445).

\section{LITERATURE CITED}

Baker L, Reeve M (1974) Laboratory culture of the lobate ctenophore Mnemiopsis mccradyi with notes on feeding and fecundity. Mar Biol 26:57-62

> Beerli P (2006) Comparison of Bayesian and maximum-likelihood inference of population genetic parameters. Bioinformatics 22:341-345

> Beerli P, Palczewski M (2010) Unified framework to evaluate panmixia and migration direction among multiple sampling locations. Genetics 185:313-326

Belkhir K, Borsa P, Chikhi L, Raufaste N, Bonhomme F (1996) GENETIX 4.05, logiciel sous Windows TM pour la génétique des populations. Laboratoire Génome, Populations, Interactions, CNRS UMR 5000. Université de Montpellier II, Montpellier

Benjamini Y, Hochberg Y (1995) Controlling the false discovery rate: a practical and powerful approach to multiple testing. J Roy Stat Soc B Met:289-300

Bertorelle G, Bruford MW, Hauffe HC, Rizzoli A, Vernesi C (2009) Population genetics for animal conservation. Cambridge University Press, New York, NY

Bilio M, Niermann U (2004) Is the comb jelly really to blame for it all? Mnemiopsis leidyi and the ecological concerns about the Caspian Sea. Mar Ecol Prog Ser 269:173-183

Boero F, Putti M, Trainito E, Prontera E, Piraino S, Shiganova TA (2009) First records of Mnemiopsis leidyi (Ctenophora) from the Ligurian, Thyrrhenian and Ionian Seas (Western Mediterranean) and first record of Phyllorhiza punctata (Cnidaria) from the Western Mediterranean. Aquat Invasions 4:675-680

- Brown JE, Stepien CA (2009) Invasion genetics of the Eurasian round goby in North America: tracing sources and spread patterns. Mol Ecol 18:64-79

Cavalli-Sforza LL, Edwards AWF (1967) Phylogenetic analysis. Models and estimation procedures. Am J Hum Genet 19:233-257

Costello J, Sullivan B, Gifford D, Van Keuren D, Sullivan L (2006) Seasonal refugia, shoreward thermal amplification, and metapopulation dynamics of the ctenophore Mnemiopsis leidyi in Narragansett Bay, Rhode Island. Limnol Oceanogr 51:1819-1831

Costello J, Bayha K, Mianzan H, Shiganova T, Purcell J (2012) Transitions of Mnemiopsis leidyi (Ctenophora: Lobata) from a native to an exotic species: a review. Hydrobiologia 690:21-46

> Darling JA, Bagley MJ, Roman J, Tepolt CK, Geller JB (2008) Genetic patterns across multiple introductions of the globally invasive crab genus Carcinus. Mol Ecol 17: 4992-5007

Daskalov GM, Grishin AN, Rodionov S, Mihneva V (2007) Trophic cascades triggered by overfishing reveal possible mechanisms of ecosystem regime shifts. Proc Natl Acad Sci USA 104:10518-10523 
Dias PC (1996) Sources and sinks in population biology. Trends Ecol Evol 11:326-330

Dumont HJ, Shiganova TA, Niermann U (2004) Aquatic invasions in the Black, Caspian, and Mediterranean seas: the ctenophores Mnemiopsis leidyi and Beroe in the Ponto-Caspian and other aquatic invasions. Kluver, Dordrecht

Ellstrand NC, Schierenbeck KA (2000) Hybridization as a stimulus for the evolution of invasiveness in plants? Proc Natl Acad Sci USA 97:7043

Estoup A, Guillemaud T (2010) Reconstructing routes of invasion using genetic data: why, how and so what? Mol Ecol 19:4113-4130

Evanno G, Regnaut S, Goudet J (2005) Detecting the number of clusters of individuals using the software STRUCTURE: a simulation study. Mol Ecol 14:2611-2620

Faasse MA, Bayha KM (2006) The ctenophore Mnemiopsis leidyi A. Agassiz 1865 in coastal waters of the Netherlands: an unrecognized invasion? Aquat Invasions 1: 270-277

Felsenstein J (1993) PHYLIP (phylogeny inference package), version 3.5. http://evolution.genetics.washington. edu/phylip.html

Finenko GA, Kideys AE, Anninsky BE, Shiganova TA and others (2006) Invasive ctenophore Mnemiopsis leidyi in the Caspian Sea: feeding, respiration, reproduction and predatory impact on the zooplankton community. Mar Ecol Prog Ser 314:171-185

Fuentes VL, Angel DL, Bayha KM, Atienza D and others (2010) Blooms of the invasive ctenophore, Mnemiopsis leidyi, span the Mediterranean Sea in 2009. Hydrobiologia 645:23-37

> Galil BS, Kress N, Shiganova TA (2009) First record of Mnemiopsis leidyi A. Agassiz, 1865 (Ctenophora; Lobata; Mnemiidae) off the Mediterranean coast of Israel. Aquat Invasions 4:357-360

Galil BS, Gevili R, Shiganova T (2011) Not far behind: first record of Beroe ovata Mayer, 1912 (Ctenophora: Beroida: Beroidae) off the Mediterranean coast of Israel. Aquat Invasions 6:S89-S90

> Ghabooli S, Shiganova TA, Zhan AB, Cristescu ME, Eghtesadi-Araghi P, MacIsaac HJ (2011) Multiple introductions and invasion pathways for the invasive ctenophore Mnemiopsis leidyi in Eurasia. Biol Invasions 13: 679-690

Giribet G, Dunn CW, Edgecombe GD, Rouse GW (2007) A modern look at the animal tree of life. Zootaxa 1668: 61-79

Gorokhova E, Lehtiniemi M, Viitasalo-Frösen S, Haddock SHD (2009) Molecular evidence for the occurrence of ctenophore Mertensia ovum in the northern Baltic Sea and implications for the status of the Mnemiopsis leidyi invasion. Limnol Oceanogr 54:2025-2033

Hejnol A, Obst M, Stamatakis A, Ott M and others (2009) Assessing the root of bilaterian animals with scalable phylogenomic methods. Proc R Soc Lond B Biol Sci 276: 4261-4270

> Ivanov VP, Kamakin AM, Ushivtzev VB, Shiganova T and others (2000) Invasion of the Caspian Sea by the comb jellyfish Mnemiopsis Leidyi (Ctenophora). Biol Invasions 2:255-258

Jaspers C, Møller LF, Kiørboe T (2011) Salinity gradient of the Baltic Sea limits the reproduction and population expansion of the newly invaded comb jelly Mnemiopsis leidyi. PLoS ONE 6:e24065
Jaspers C, Haraldsson M, Lombard F, Bolte S, Kiorboe T (2013) Seasonal dynamics of early life stages of invasive and native ctenophores give clues to invasion and bloom potential in the Baltic Sea. J Plankton Res

> Javidpour J, Sommer U, Shiganova T (2006) First record of Mnemiopsis leidyi A. Agassiz 1865 in the Baltic Sea. Aquat Invasions 1:299-302

Kalinowski ST (2005) hp rare 1.0: a computer program for performing rarefaction on measures of allelic richness. Mol Ecol Notes 5:187-189

Kideys AE (2002) Fall and rise of the Black Sea ecosystem. Science 297:1482-1484

Kideys AE, Niermann U (1994) Occurrence of Mnemiopsis along the Turkish coast. ICES J Mar Sci 51:423-427

Kolbe JJ, Glor RE, Schettino LR, Lara AC, Larson A, Losos JB (2004) Genetic variation increases during biological invasion by a Cuban lizard. Nature 431:177-181

- Lack JB, Greene DU, Conroy CJ, Hamilton MJ, Braun JK, Mares MA, Van den Bussche RA (2012) Invasion facilitates hybridization with introgression in the Rattus rattus species complex. Mol Ecol 21:3545-3561

Lange C, Hemmrich G, Klostermeier UC, Lopez-Quintero JA and others (2010) Defining the origins of the NODlike receptor system at the base of animal evolution. Mol Biol Evol 28:1687

Leberg PL (2002) Estimating allelic richness: effects of sample size and bottlenecks. Mol Ecol 11:2445-2449

> Lee PLM, Dawson MN, Neill SP, Robins PE, Houghton JDR, Doyle TK, Hays GC (2013) Identification of genetically and oceanographically distinct blooms of jellyfish. J R Soc Interface 10:20120920

> Lehtiniemi M, Lehmann A, Javidpour J, Myrberg K (2012) Spreading and physico-biological reproduction limitations of the invasive American comb jelly Mnemiopsis leidyi in the Baltic Sea. Biol Invasions 14:341-354

> Licandro P, Conway D, Yahia MND, De Puelles MLF and others (2010) A blooming jellyfish in the northeast Atlantic and Mediterranean. Biol Lett 6:688-691

Oliveira OMP (2007) The presence of the ctenophore Mnemiopsis leidyi in the Oslofjorden and considerations on the initial invasion pathways to the North and Baltic Seas. Aquat Invasions 2:185-189

Page RDM (1996) TreeView. An application to display phylogenetic trees on personal computer. Comp Appl Biol Sci 12:357-358

Pang K, Martindale MQ (2008a) Developmental expression of homeobox genes in the ctenophore Mnemiopsis leidyi. Dev Genes Evol 218:307-319

Pang K, Martindale MQ (2008b) Comb jellies (Ctenophora): a model for basal metazoan evolution and development. CSH Protocols 2008 (11): pdb.emo106

Pritchard JK, Stephens M, Donnelly P (2000) Inference of population structure using multilocus genotype data. Genetics 155:945

Purcell JE, Shiganova TA, Decker MB, Houde ED (2001) The ctenophore Mnemiopsis in native and exotic habitats: US estuaries versus the Black Sea basin. Hydrobiologia 451:145-176

Purcell JE, Uye S, Lo WT (2007) Anthropogenic causes of jellyfish blooms and their direct consequences for humans: a review. Mar Ecol Prog Ser 350:153-174

Reeve MR, Syms MA, Kremer P (1989) Growth dynamics of a ctenophore (Mnemiopsis) in relation to variable food supply. I. Carbon biomass, feeding, egg production, growth and assimilation efficiency. J Plankton Res 11:535-552 
Reusch TBH, Bolte S, Sparwel M, Moss AG, Javidpour J (2010) Microsatellites reveal origin and genetic diversity of Eurasian invasions by one of the world's most notorious marine invader, Mnemiopsis leidyi (Ctenophora). Mol Ecol 19:2690-2699

Richardson AJ, Bakun A, Hays GC, Gibbons MJ (2009) The jellyfish joyride: causes, consequences and management responses to a more gelatinous future. Trends Ecol Evol 24:312-322

Rius M, Pascual M, Turon X (2008) Phylogeography of the widespread marine invader Microcosmus squamiger (Ascidiacea) reveals high genetic diversity of introduced populations and non-independent colonizations. Divers Distrib 14:818-828

Roman J, Darling JA (2007) Paradox lost: genetic diversity and the success of aquatic invasions. Trends Ecol Evol 22:454-464

Roohi A, Kideys AE, Sajjadi A, Hashemian A and others (2010) Changes in biodiversity of phytoplankton, zooplankton, fishes and macrobenthos in the Southern Caspian Sea after the invasion of the ctenophore Mnemiopsis leidyi. Biol Invasions 12:2343-2361

Sakai AK, Allendorf FW, Holt JS, Lodge DM and others (2001) The population biology of invasive species. Ann Rev Ecol Syst 32:305-332

Sax DF, Brown JH (2000) The paradox of invasion. Glob Ecol Biogeogr 9:363-371

Schaber M, Haslob H, Huwer B, Harjes A and others (2011) The invasive ctenophore Mnemiopsis leidyi in the central Baltic Sea: seasonal phenology and hydrographic influence on spatio-temporal distribution patterns. J Plankton Res 33:1053-1065

Schlitzer R (2002) Interactive analysis and visualization of

Editorial responsibility: Philippe Borsa,

Montpellier, France geoscience data with Ocean Data View. Comp Geosci 28:1211-1218

Shiganova TA, Bulgakova YV (2000) Effects of gelatinous plankton on Black Sea and Sea of Azov fish and their food resources. ICES J Mar Sci: Journal du Conseil 57: 641-648

Shiganova TA, Mirzoyan ZA, Studenikina EA, Volovik SP and others (2001) Population development of the invader ctenophore Mnemiopsis leidyi, in the Black Sea and in other seas of the Mediterranean basin. Mar Biol 139: $431-445$

Siapatis A, Giannoulaki M, Valavanis VD, Palialexis A, Schismenou E, Machias A, Somarakis S (2008) Modelling potential habitat of the invasive ctenophore Mnemiopsis leidyi in Aegean Sea. Hydrobiologia 612:281-295

Stopar K, Ramsak A, Trontelj P, Malej A (2010) Lack of genetic structure in the jellyfish Pelagia noctiluca (Cnidaria: Scyphozoa: Semaeostomeae) across European seas. Mol Phylogenet Evol 57:417-428

Suarez AV, Tsutsui ND (2008) The evolutionary consequences of biological invasions. Mol Ecol 17:351-360

> Sakai AK, Allendorf FW, Holt JS, Lodge DM, Molofsky J, With KA, Baughman S, Cabin RJ, Cohen JE, Ellstrand NC (2001) The population biology of invasive species. Annu Rev Ecol Syst 32:305-332

Van Ginderdeuren K, Hostens K, Hoffman S, Vansteenbrugge L and others (2012) Distribution of the invasive ctenophore Mnemiopsis leidyi in the Belgian part of the North Sea. Aquat Invasions 7:163-169

Vinogradov ME, Shushkina EA, Musaeva EI, Sorokin PY (1989) Ctenophore Mnemiopsis leidyi (A. Agassiz) (Ctenophora, lobata): new settlers in the Black Sea. Oceanology 29:293-299

Submitted: February 29, 2012; Accepted: March 4, 2013 Proofs received from author(s): May 31, 2013 